\title{
Enzymatic Nitrene Transfer/Sigmatropic Rearrangement to Access Allylic Amines
}

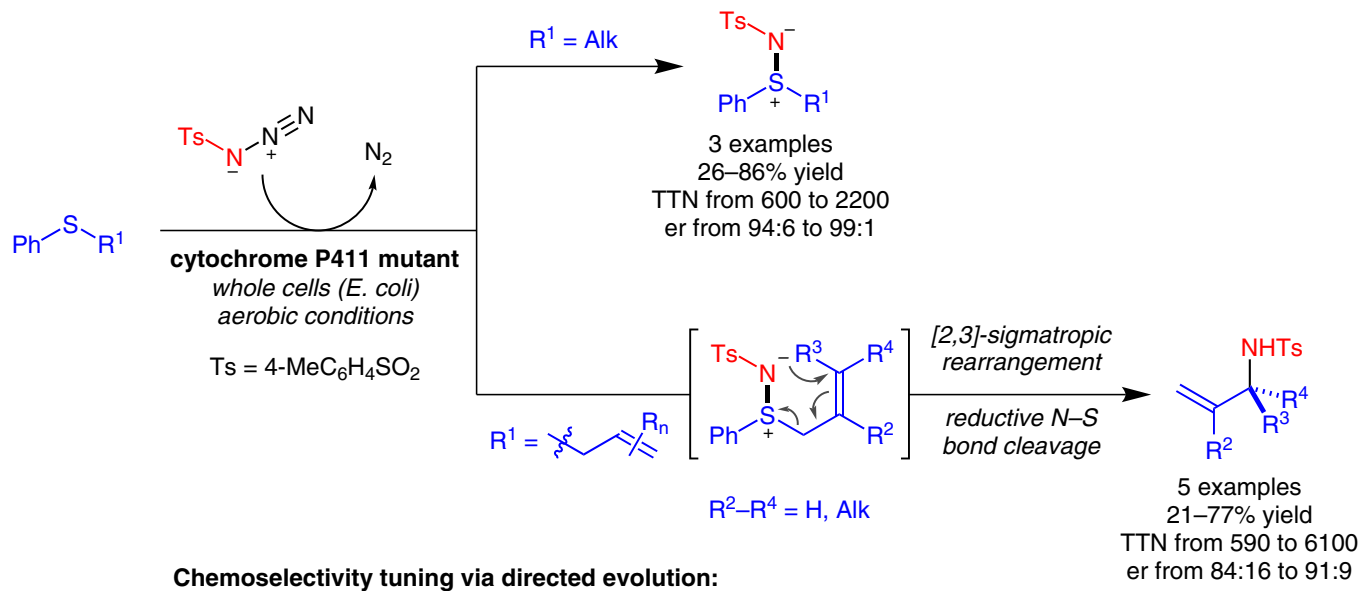

enzymes

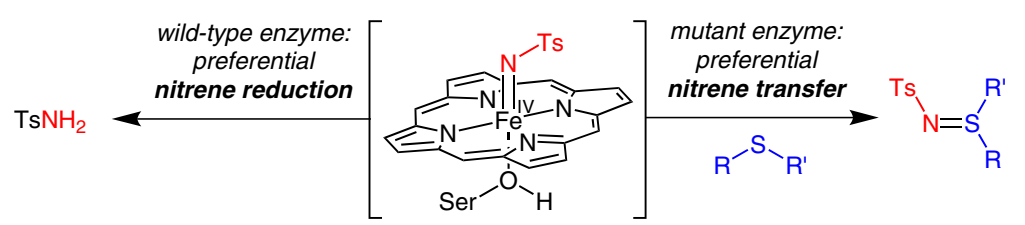

Selected examples:
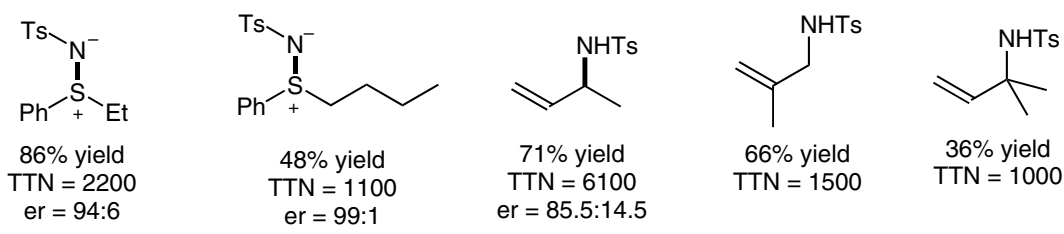

$36 \%$ yield

er $=94: 6$

er $=99: 1$

er $=85.5: 14.5$

TTN $=1500$

$\mathrm{TTN}=1000$

TTN...total turnover number

Significance: Arnold and co-workers report an enzymatic synthesis of allylic amines through a sulfimidation/[2,3]-sigmatropic rearrangement of phenyl allyl sulfides with tosyl azide. A mutant variant of cytochrome P411 from Bacillus megaterium efficiently catalyzes a highly enantioselective nitrene transfer to the sulfides, and permits a subsequent rearrangement with partial retention of the stereochemical information. In a scale-up experiment with reduced catalyst loading, $0.1 \mathrm{mmol}$ of substrate was converted into the corresponding allylic amine in $71 \%$ yield and a remarkable total turnover number of 6100 .

SYNFACTS Contributors: Benjamin List, Lucas Schreyer Synfacts 2016, 12(06), 0635 Published online: 17.05.2016 Dol: 10.1055/s-0035-1562137; Reg-No.: B02216SF
Comment: The authors have successfully employed directed evolution to achieve a chemoselective nitrene transfer over the competing reduction. Furthermore, they achieved a sigmatropic rearrangement of the intermediate allylic sulfimides, a process unknown in wild-type biological systems. 